\title{
Psychopharmacological Options in the Management of Lupus Cerebritis: A Case Report AK Sarangi ${ }^{1}$, K De Castro ${ }^{2}$, RC Gibson ${ }^{1}$, GA Lowe ${ }^{1}$, TS Ferguson ${ }^{2}$
}

\begin{abstract}
The purpose of this paper is to report a case of a 19 year old woman who presented with prominent hyperactive delirium and Systemic Lupus Erythematosus (SLE). The psychiatric drug treatment and rational for its usage are discussed. This case illustrates the importance of differentiating between the psychiatric manifestations of chronic high dose steroid use and a psychosis secondary to brain involvement of SLE. Lupus cerebritis should be included in the provisional diagnosis of the young woman with acute onset of psychosis and should be carefully differentiated from a psychotic disorder especially if the patient has no clear period of premorbid psychiatric pathology or a genetic predisposition for a primary psychotic disorder.
\end{abstract}

Keywords: Cerebritis, psychiatry, psychopharmacology, SLE

From: ${ }^{1}$ Department of Community Health and Psychiatry, The University of the West Indies, and ${ }^{2}$ Department of Medicine, The University of the West Indies, Kingston 7, Jamaica, West Indies.

Correspondence: Dr A Sarangi, Department of Psychiatry, University Hospital of the West Indies, Kingston 7, Jamaica, West Indies. Email: aks_sarangi@ hotmail.com 


\section{INTRODUCTION}

Systemic Lupus Erythematosus (SLE) is a chronic inflammatory autoimmune disorder of the connective tissue. It can affect multiple internal organs, including the kidneys, heart, lungs and brain. Lupus cerebritis can present with a myriad of neuropsychiatric manifestations (NPSLE) and these have been reported to occur in $21-95 \%$ of patients diagnosed with lupus at some stage of their illness (1). Fewer than 40-50\% of 19 NPSLE syndromes are due to underlying CNS lupus activity (primary NPSLE) etc (2) (3). The remaining syndromes result from indirect causes such as metabolic effects and infections (4;5). NPSLE syndromes include seizure disorders, cerebrovascular disease, cognitive dysfunction, mood disorder and psychosis (4;6). At times cerebral involvement may result in the first symptoms of underlying primary SLE. The diagnosis of NPSLE may be overlooked especially if the patient lacks more widespread systemic involvement of SLE such as a typical malar rash. The management for this condition is usually multimodal and includes input from the medicine service as well as the psychiatry team.

\section{CASE REPORT}

A 19 year old young woman with a history of SLE diagnosed in January 2014 presented to the University Hospital of The West Indies (UHWI) and presented in May 2015 with a two week history of not eating and not sleeping well along with a reluctance to maintain her personal hygiene. Her relatives also reported that she was aggressive towards them with periods of intermittent outbursts and apparently responding to unseen stimuli during the period. The patient also tended to have decreased communication overall and intermittently threatened her family 
members with knives. Sharp objects had to be hidden from her. She did not sleep at nights but paced back and forth in the house. Her appetite was also noted to be significantly decreased.

The patient was taken to a local health center where olanzapine $20 \mathrm{mg}$ daily and diazepam $5 \mathrm{mg}$ at nights were prescribed. On that regime the patient did not demonstrate any improvement. Upon review by the psychiatry service at the (UHWI), Accident and Emergency Department, the patient was noted to be appropriately attired in casual wear however her attitude and behaviour were found to be very uncooperative. She was placed in 4 point restraints with her arms flexed but had no resistance to passively placing both upper limbs to her side. When attempts were made to evaluate her mental status she would only respond by shaking her head or would answer in monosyllables. Her affect was quite labile ranging from restricted to quite irritable. Formal assessment of her thought process, content and perception was difficult due to the paucity of speech which she exhibited. However, historically she had persecutory delusions against her relatives and during the interview process was seen actively responding to unseen stimuli.

With regard to her physical examination and vital signs her temperature was $37.1^{\circ} \mathrm{C}$, pulse rate was 115 beats/min, respiratory rate was 20 breaths/min and blood pressure was 148/100mmHg. Her significant findings included dry mucous membranes, a malar hyper pigmented rash to her face and tenderness in the suprapubic region. A lumbar puncture under sterile conditions was performed while the patient was in the Accident and Emergency department which confirmed the findings of cerebral lupus which were elevated levels of white cells and protein and positive antinuclear antibody. The results of the lumbar puncture also helped rule out a central nervous system infection, therefore the patient was admitted to the Internal Medicine ward with the diagnosis of lupus cerebritis. The patient's blood and CSF results on presentation are demonstrated in Table 1. 
Further immunological studies were conducted in A\&E on day 2 after post duty medicine rounds prior to patient being transferred to the medical ward based on which a diagnosis of lupus cerebritis was confirmed. These results are also presented in Table 1. The patient's systemic lupus erythematosus disease activity index (SLEDAI score) which is a marker of lupus disease activity was also calculated. Disease activity is scored based on 24 items, 16 items of which are clinical syndromes such as seizures, psychosis, visual disturbance, rash, alopecia and neurological problems and 8 of which are laboratory results such as urinalysis testing, blood complement levels, low platelets and low white blood cell count. The patient's SLEDAI score was calculated to be 12 (8-psychosis, 2-rash, 2-alopecia). A score of greater than 3 indicates a mild or moderate flare while a score greater than 12 indicates a severe flare.

She was initially diagnosed by the psychiatry resident in Accident and Emergency with a Psychotic Disorder Secondary to a General Medical Condition (lupus cerebritis) with severe impairment in functioning. Quetiapine $50 \mathrm{mg}$ twice a day was prescribed for her on day 1 and she was admitted to the medical ward for further management and to be co managed by the psychiatric team. On day 3 changes were made to her medication regime and she was placed on haloperidol $5 \mathrm{mg}$ at nights and olanzapine $5 \mathrm{mg}$ at nights. However a decision was made to maintain the patient only on haloperidol $5 \mathrm{mg}$ at nights and discontinue olanzapine subsequently on day 5 while on the medical ward. The patient was also placed on a regime of mycophenolate mofetil 500mg po twice daily, hydroxychloroquine $20 \mathrm{mg}$ once daily and prednisone $60 \mathrm{mg}$ po once daily as immunosuppressive agents.

The dose of prednisone was greater than $0.5 \mathrm{mg} / \mathrm{kg} /$ day which exceeded double the dose of steroids that patient was taking upon presentation. Due to the new neurological manifestation, 
requirement of doubling the dose of prednisone and use of prednisone $>0.5 \mathrm{mg} / \mathrm{kg} / \mathrm{day}$, the patient was deemed to meet the criteria of a severe flare of SLE.

Upon review by the consultation psychiatry liaison team while on the medical ward, the patient continued to require 2 point restraints after attempting to pull out her intravenous access repeatedly. She had minimal response to questioning and appeared tearful. A decision was made to increase the haloperidol dosage to $2.5 \mathrm{mg}$ in the mornings and $5 \mathrm{mg}$ po at nights on day 8 and at that time, she was also commenced on benztropine $2 \mathrm{mg}$ orally twice daily. During the subsequent days while being followed up by the psychiatry service, she appeared confused and disoriented in time, place and person. The patient increasingly showed resistance to taking any oral medications and had to be given intramuscular sedation. Her haloperidol dosage was further increased to $30 \mathrm{mg}$ daily on day 12 and her diagnosis was reviewed and amended to delirium secondary to Lupus Cerebritis. She was reviewed and consulted on by the neurologist who suggested that it could take 4-6 weeks for any improvement in her neurological manifestations secondary to lupus cerebritis and recommended continuation of haloperidol and benztropine.

The patient's mental status however deteriorated further and she began to express significant affective symptoms including grandiose delusions stating that she was Cleopatra and that she owned a kingdom for herself. Subsequent to this the medication therapy was reviewed and it was decided to discontinue haloperidol and recommence quetiapine at $400 \mathrm{mg}$ twice daily on day 28. However in the subsequent days the patient's status worsened and upon review by the psychiatry team on day 45 of admission she was transferred to the psychiatry ward. After transfer to the psychiatric unit the patient was placed on olanzapine $20 \mathrm{mg}$ orally twice daily on day 46 however she remained disoriented. She required 24 hour intensive nursing care as she had a tendency to leave the ward when unsupervised and continued to have intermittent loud outbursts. 
Finally, her regime was again changed to haloperidol 5mg every 6 hours and diphenhydramine $25 \mathrm{mg}$ twice daily on day 48 . No changes were made to the patient's immunosuppressive regime as she remained on Prednisone $60 \mathrm{mg}$ once daily and $500 \mathrm{mg}$ twice daily of mycophenolate mofetil. There was slow and steady and gradual improvement in the patient's condition over her 80 day admission and she showed significant improvement in her cognition and orientation which was mirrored by a decrease in her ESR to the point where she was able to be discharged to her parents with continued care at home. The patient's blood results upon discharge are presented below.

\section{DISCUSSION}

The neuropsychiatric manifestations of lupus cerebritis cause significant distress to the patient, clinician and caregivers. The differentiation of psychosis in the context of NPSLE from a primary psychotic disorder is critical as both these entities may first present around the same age. Thus far no official recommendations or guidelines have been published to guide the psychiatric treatment of patients with lupus cerebritis who exhibit significant psychotic or manic symptoms. Most of the management decisions that have been made in clinical practice are based on the profile of the patient and any associated co morbidities.

Previous suggestions have been made through case reports regarding pharmacological management of neuropsychiatric systemic lupus erythematosus. One study recommended use of olanzapine and quetiapine in this group of patients (6). Good sense suggests that the same precautions and monitoring that is undertaken for the general psychiatric population should be 
employed when using psychotropic drugs in this patient category. Some of the considerations have even greater relevance to patients with lupus cerebritis and their well being.

Great care must be taken to not precipitate a seizure in these patients who are already significantly predisposed to these events because of the extensive cerebral involvement. Keeping this in mind, chlorpromazine (CPZ) should generally be avoided in this patient subgroup. Chlorpromazine is also known to cause drug induced lupus and contributes to photosensitivity which is quite debilitating (7). Haloperidol has been shown to have the least risk associated with seizure initiation (8). Further, patients with SLE are already more at risk for development of metabolic syndrome secondary to corticosteroid therapy. Thus, they require regular monitoring of their body mass index, lipids and fasting glucose especially if they are co managed with atypical antipsychotics. Significant drug to drug reactions must be carefully monitored for these patients who are often on a cocktail of medications are at risk for various side effects, some of which are life threatening such as the Steven-Johnson Syndrome.

No difference in efficacy has been demonstrated between the traditional and atypical antipsychotics medications with regard to psychotic symptoms (9) though it has been found that the atypical antipsychotics provide the added benefit of acting as mood stabilizers which may be important in managing mood symptoms in patients with lupus cerebritis or steroid induced mania (10). Alternatively, clinicians use the addition of an anticonvulsant mood stabilizer such as valproic acid to address the mood issue.

Another consideration is that the traditional antipsychotics may exacerbate neuropsychiatric movement disorders. Anticholinergic agents may be added to assist with managing these movement disorders. However, the use of anticholinergic agents in patients with lupus cerebritis presents another dilemma for clinicians as they present the added risk of causing 
confusion, coma and seizures especially in overdose. This is weighed against the necessity of using these agents as a preventive strategy to counteract any movement disorders such as neuroleptic induced parkinsonism the patient may develop. This holds especially true for typical antipsychotics such as Haloperidol (11). A good practice would be to use the lowest effective dosage possible and titrate upwards only if necessary. An alternative is to use a different kind of antiparkinsonian agent e.g. diphenhydramine as in this case.

\section{CONCLUSION}

This case report highlights the potential value of using Haloperidol at low/moderate dosages as a first line candidate treatment in patients with lupus cerebritis who present with significant psychotic or manic symptoms.

\section{REFERENCES}

1. Hanly JG. Diagnosis and management of neuropsychiatric SLE. Nat Rev Rheumatol 2014 June;10(6):338-47.

2. Mak A, Ho RCM, Lau CS. Clinical implications of neuropsychiatric systemic lupus erythematosus. Advances in Psychiatric Treatment 2009 October 30;15(6):451-8.

3. ACR. The American College of Rheumatology nomenclature and case definitions for neuropsychiatric lupus syndromes. Arthritis Rheum 1999 April;42(4):599-608.

4. Feinglass EJ, Arnett FC, Dorsch CA, Zizic TM, Stevens MB. Neuropsychiatric manifestations of systemic lupus erythematosus: diagnosis, clinical spectrum, and relationship to other features of the disease. Medicine (Baltimore) 1976 July;55(4):32339. 
5. Raj R, Murin S, Matthay RA, Wiedemann HP. Systemic lupus erythematosus in the intensive care unit. Crit Care Clin 2002 October;18(4):781-803.

6. Nayak RB, Bhogale GS, Patil NM, Chate SS. Psychosis in patients with systemic lupus erythematosus. Indian J Psychol Med 2012 January;34(1):90-3.

7. Harth Y, Rapoport M. Photosensitivity associated with antipsychotics, antidepressants and anxiolytics. Drug Saf 1996 April;14(4):252-9.

8. Pisani F, Oteri G, Costa C, Di RG, Di PR. Effects of psychotropic drugs on seizure threshold. Drug Saf 2002;25(2):91-110.

9. Foussias G, Remington G. Antipsychotics and schizophrenia: from efficacy and effectiveness to clinical decision-making. Can J Psychiatry 2010 March;55(3):117-25.

10. Manschreck TC, Boshes RA. The CATIE schizophrenia trial: results, impact, controversy. Harv Rev Psychiatry 2007 September;15(5):245-58.

11. Rybakowski JK, Vansteelandt K, Remlinger-Molenda A, Fleischhacker WW, Kahn RS, Peuskens J. Extrapyramidal symptoms during treatment of first schizophrenia episode: results from EUFEST. Eur Neuropsychopharmacol 2014 September;24(9):1500-5. 
Table 1: Summary of changes in psychotropic regime

\begin{tabular}{ll}
\hline Day of admission to hospital & Psychotropic medications prescribed \\
\hline Day 1 & Quetiapine $50 \mathrm{mg}$ po bd \\
Day 3 & $\begin{array}{l}\text { Haloperidol } 5 \mathrm{mg} \text { po nocte } \\
\text { Olanzapine } 5 \mathrm{mg} \text { po nocte }\end{array}$ \\
Day 8 & $\begin{array}{l}\text { Haloperidol } 2.5 \mathrm{mg} \text { po am } \\
\text { Haloperidol } 5 \mathrm{mg} \text { po nocte } \\
\text { Cogentin } 2 \mathrm{mg} \text { po bd }\end{array}$ \\
Day 12 & $\begin{array}{l}\text { Haloperidol } 10 \mathrm{mg} \text { po tds } \\
\text { Cogentin } 2 \mathrm{mg} \text { po bd }\end{array}$ \\
Day 28 & $\begin{array}{l}\text { Discontinue Haloperidol } \\
\text { Commence Quetiapine } 400 \mathrm{mg} \text { po bd }\end{array}$ \\
Day 46 & $\begin{array}{l}\text { Discontinue Quetiapine } \\
\text { Commence Olanzapine } 20 \mathrm{mg} \text { po bd }\end{array}$ \\
Day 48 & Haloperidol $5 \mathrm{mg}$ po q6h \\
& DPH $25 \mathrm{mg}$ po bd
\end{tabular}


Table 2. Results of selected laboratory investigations performed on the patient

\begin{tabular}{|c|c|c|c|}
\hline \multirow[t]{2}{*}{ Test } & \multicolumn{3}{|c|}{ Results } \\
\hline & Day 1 & Day 2 & Day 80 (discharge) \\
\hline $\mathrm{Na}$ & 140 & & \\
\hline $\mathrm{K}$ & 4.4 & & \\
\hline $\mathrm{HCO} 3$ & 22 & & \\
\hline $\mathrm{Cl}$ & 100 & & \\
\hline Urea & 1.2 & & \\
\hline Creat & 42 & & \\
\hline $\mathrm{Hb}$ & 11.4 & & \\
\hline PCV & 0.36 & & \\
\hline WBC & 7.1 & & \\
\hline Platelets & 306 & & \\
\hline ESR & 100 & & 30 \\
\hline CSF colour & Clear, colourless & & \\
\hline CSF Protein & 367 & & \\
\hline CSF Glucose & 3.9 & & \\
\hline CSF Rbc & 4.9 & & \\
\hline CSF Cells & $3 \mathrm{wbc} / \mathrm{mm} 3$ & & \\
\hline Serum Glucose & 4.9 & & \\
\hline C3 & & $123[72-356 \mathrm{mg} / \mathrm{dl}]$ & $78.7[72-356 \mathrm{mg} / \mathrm{dll}]]$ \\
\hline C4 & & $17.7[10-40 \mathrm{mg} / \mathrm{dl}]$ & $12.1[10-40 \mathrm{mg} / \mathrm{dll}]$ \\
\hline CRP & & $0.19[<1 \mathrm{mg} / \mathrm{dl}]$ & \\
\hline dsDNA & & Negative & Negative \\
\hline
\end{tabular}

